\title{
Hybrid Ontology-based knowledge with multi-objective optimization model framework for Decision Support System in intercropping
}

\author{
Kornkanok Phoksawat ${ }^{* 1,2}$, Massudi Mahmuddin ${ }^{2}$ \\ ${ }^{1}$ Department of Information System, Rajanangala University of Technology Srivijaya, 80110, Thailand \\ ${ }^{2}$ School of Computing, Universiti Utara Malaysia, Sintok, 06010, Malaysia
}

\author{
A R T I C L E I N F O \\ Article history: \\ Received: 30 May, 2017 \\ Accepted: 18 July, 2017 \\ Online: 05 August, 2017

Keywords:
Ontology-based knowledge
Multi-Objective Optimization
Multi-Criteria Selection problem
Intercropping in rubber plantation
Decision Support System \\ Keywords: \\ Ontology-based knowledge \\ Multi-Objective Optimization \\ Intercropping in rubber plantation \\ Decision Support System
}

\begin{abstract}
A B S T R A C T
The problem of multi-criteria or multi-objective intercropping crop planning makes it vital to consider all related factors under the constraints that will produce the highest revenue and minimum cost. Principles of intercropping elements including soil type, plant area, plant diseases, planting and harvesting time and economics factors (e.g. price, cost) are some of the factors in making decisions. Intercropping is important in the situation such as during inability to harvest main crops, co-cultivation to increase productivity, or even to increase extra revenue. Therefore, the decision-making system requires a wise decision support system, which can advise farmers on economics matters. In this article, we present the decision support system (DSS) model framework for planting rubber with intercropping by a hybrid approach using ontology-based knowledge consuming rule concepts and relationships for intercropping with integrated multi-objectives optimization to recommend the crop to be planted and the suitable proportion of planting areas or planting co-suited to the rubber plantation of farmers. This approach could be applied as a guideline for another field, such as production problems or other resource allocation issues.
\end{abstract}

\section{Introduction}

This paper is an extension of the original work which was presented in 2016 at the International Computer Science and Engineering Conference (ICSEC) [1]. This article explains in more detail about the Research Framework and Research Methodology.

The agriculture in Thailand comprises of 45.84 million acres or $35.7 \%$ of area of the country where $25.9 \%$ of households are farmers with an average 7.76 acres per person. These farmers are divided into $79.1 \%$ monoculture farmers and another $19.9 \%$ integrated farming. Other main agricultural activities in Thailand are livestock production, fish or other important aquatic animal raising or salt ponds [2].

Recently, the weather uncertainty and low price of the agricultural products especially hits the monoculture farmer severely. This can be seen in rubber planting (rubber is a major Thailand economic crops), where the rubber price affected the

${ }^{*}$ Corresponding Author: Kornkanok Phoksawat, Department of Information System, Rajanangala University of Technology Srivijaya, 80110, Thailand Email: kornkanok.p@rmutsv.ac.th

www.astesj.com

https://dx.doi.org/10.25046/aj0203172 farmers. In 2015, the rubber prices dropped $20.1 \%$ as compared to the previous year which made export of rubber drop by THB 52,000 million (21.4\% decrease) [3].

Southern Thailand is the main producer of rubber in Thailand, and $70 \%$ of the labor in this region are rubber farmers in monoculture. The farmers have been impacted from this terrible situation where their income in 2015 has declined THB 33,000 million (or $17.7 \%$ ) as compared to on the previous year. As a result, this decline has raised the household's average debt from THB 134,893 per household in 2013 to THB 153,144 in the first half of 2015. Findings from the Bank for Agriculture and Cooperative shows that the farmers were giving some signal that their income is unsustainable for them to pay the bills normally due to the fluctuation of rubber's price since 2014 and many of them decided to uproot their rubber trees and preferred to plant other more profitable crops. In this condition, monoculture farming might not be the possible answer although the economic return was high, at the same time, the risk is still there when the price fluctuates by the market [4]. 


\section{K. Phoksawt et al. / Advances in Science, Technology and Engineering Systems Journal Vol. 2, No. 3, 1363-1371 (2017)}

Due to that, it is unwise to stay in the type of farming approach which only concentrates on one single type of crop. One solution is to introduce or convert single monoculture into poly or intercropping farming system. In a general sense, intercropping is a planting system that uses a multiple cropping system with at least two or more crops planted in the same field/plot during a growing season [5]. In this regard, intercropping is a potential alternative for a sustainable way for the farmers to overcome the abovementioned problem by reducing risks of product price fluctuation, pathogens or insect attacks [6]. At the same time, the Thailand government have made a lot of effort to support this idea of intercropping system.

To clarify this idea, we have organized the information in figure 1 to make understandable our proposed concept to assist the farmer in this specific region or it might be applied or adopted in many other area. The interconnectedness of this model is based on the previous works that are discussed fully in Section 2. The proposed concept of integrating the overall concept framework and evaluation is discussed precisely in Sections 3 and 4 and we conclude our idea in Section 5.

\section{Related Work}

\subsection{DSS for Intercropping}

Many DSS for intercropping planning used mathematical models or are model-driven to solve this problem such as Linear Programming (LP) [7], Analytic Hierarchy process (AHP), Technique for Order Preference by Similarity to Ideal Solution (TOPSIS) or Simple additive weighting (SAW) [8] , or hybrid technique e.g. AHP and TOPSIS[9]. Nevertheless, that approach will provide just an answer to a priority of alternatives and does not answer about living space to grow. For example, the proportion of main crop and secondary crops and the calculations in this area, considering the distance between the plants and the second plants as well as the principles of the intercrop. After the system recommends a suitable priority for particular co-planting of plants, the farmers need to determine the specific area of use in order to figure out a maximum overall return. Such types of calculation may not result in an answer with maximum income under their restricted resources, and hence their opportunity of profit making is lost with not including the extraction of knowledge from experts to optimize knowledge management and decision-making.

[10] presented an integrated DSS for intercropping by using a rule-based expert system as a model. This method can be extended to cover more decision criteria to cost the cropping. The objective of the work is to manage cropping activities for improved crop production. However, approaches ignore important features due to the paper not offering price statistics for the decision. This factor is necessary for planning crops. [11] showed the model-based support by using evolutionary algorithms to solve multi-objective optimization and design of mixed farming systems aimed to maximize the operating profit and organic matter balance, and to minimize the labor requirement and soil nitrogen losses. [12] presented the goal programming for rubber plantation intercropping with tea trees. The purpose of this work is management of rubber plantation yield before getting a return for seven years.

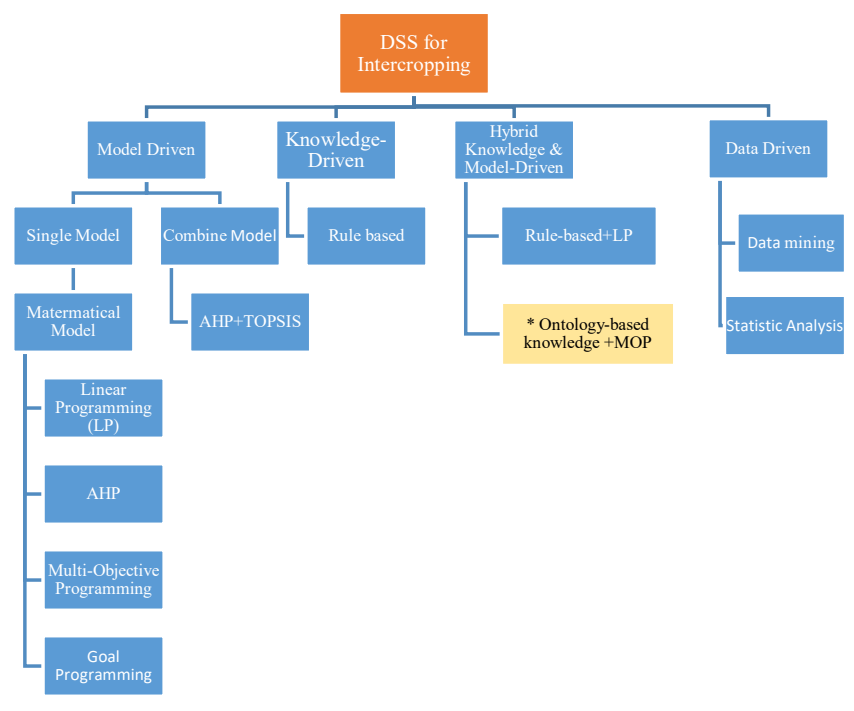

Note: * New guideline in DSS for intercropping

Figure 1 Summary of approach for DSS-Intercropping

However, literature reviews to analyze approaches in the DSS cannot ignore the knowledge-driven decisions, sometimes generically called expert systems or recommender systems because knowledge-driven DSSs might use artificial intelligence and/or some of the statistical inference technologies to suggest or recommend actions to managers. These systems have knowledge codified to provide specialized problem-solving assistance [13]. Especially in agriculture, the farmers who succeed in farming collect long-standing experiences. The knowledge has been tested through experimentation and theory and then becomes tacit knowledge which is necessary to be maintained and adopted in a knowledge-base for a decision $[14,15]$.

Therefore, the challenge is to design an ontology in the field of mixed intercropping which refers to the practice handbook of planting and a rule base from domain experts. The system can suggest the plants that grow well together in the suitable areas in a format that can be processed by a computer program. It focuses on knowledge sharing and reuse and sends related parameters about plants that suggest related plants from the recommender engine to calculate multi-objective optimization programming in order to give the answers which can support the intercropping decision supporting system for an individual agriculture.

\subsection{Ontology-knowledge base for DSS}

Ontology is a structured establishment and knowledge representation in knowledge management system or acts as a tool similar to that system whose indices were used to manage and access the subject of the question using controlled vocabularies comprising vocabularies, terms, syntax and certain rules based on making use of appropriate word patterns [16]. The results of using an ontology-based illustration of the important data structure of a DSS are the distinguishable state from what happened in the past with DSS as closed systems, the primary ontologies' objective are to determine proportionated domain models and knowledge from a variety of sources. Also, some of the inference stages of the DSS can be carried out using state-of-the-art logical reasoning performance, as rule logic providers or justification providers [17]. 


\section{K. Phoksawt et al. / Advances in Science, Technology and Engineering Systems Journal Vol. 2, No. 3, 1363-1371 (2017)}

Advantages of ontologies include seeming well suited to an evolutionary approach to domain knowledge and requirements specification [18] in contrast to traditional knowledge-based approaches, e.g. formal specification languages. Requirements management and traceability can be supported by ontologies. Semi-formal or informal approaches provide no logical formalism or model theory compared to automated validation and consistency checking which are considered as a potential benefit. Finally, the formal specification may be a prerequisite to realizing modeldriven design and implementation approaches [19].

Deciding to intercrop does not focus on finding answers to the income or economics alone but it must be based on the principles of integrated crop plants to reduce disease risk and the suitability of the area under the constraints of farmers. Therefore, this research uses ontology-based knowledge for driving DSS and providing the type of plant and design optimization model for calculating the answer for maximum income. This phase uses knowledge acquisition and ontology modeling for ontology design and experiments for economic design modeling.

Ontology-based knowledge representation that allows information sharing, reuse and collaboration on design and obsolescence issues across different organizations provides the basis for decision-making in an intercropping selection and presents concepts, relationships, and instances. To establish a comprehensive knowledge representation scheme, an ontology that can serve as the backbone of the needed information model is required [20].

Ontologies technology can be applied in the work of various systems by considering the purpose of the deployment: (1) information retrieval; (2) systems that require integration of knowledge for a basic understanding of the knowledge domain; (3) systems that have the need for knowledge reuse and such systems may be defined ontologies technology to use allowing another system to be used again by the system later. This may define semantic information that does not have contrary information of semantic ontologies taken back to another system and there is no need to explain that there is no change, such as static domain knowledge or knowledge-based system. In particular; ontology has recently been adopted in DSS in various application domains [21].

Currently, ontologies are semantic knowledge management which have been successfully implemented in DSS in various application domains, and to determine the tasks and parameters of some system modules [17], applied in knowledge management [22]. However, an ontology applies in knowledge management through the web service system, question answering [23] or DSS [24] in planting trees. Nevertheless, that answer or knowledge is about planting monoculture crops only and lacks a decision to plant mixed or intercropping to maximize income while minimizing cost in a limited farmer's resources.

\subsection{Multi-Objective Optimization Methods}

This section and figure 2 presents a summary approach for Multi-Objective Optimization. There are classical methods and Evolutionary Multi-Objective Optimization (EMO) Method [25].

www.astesi.com

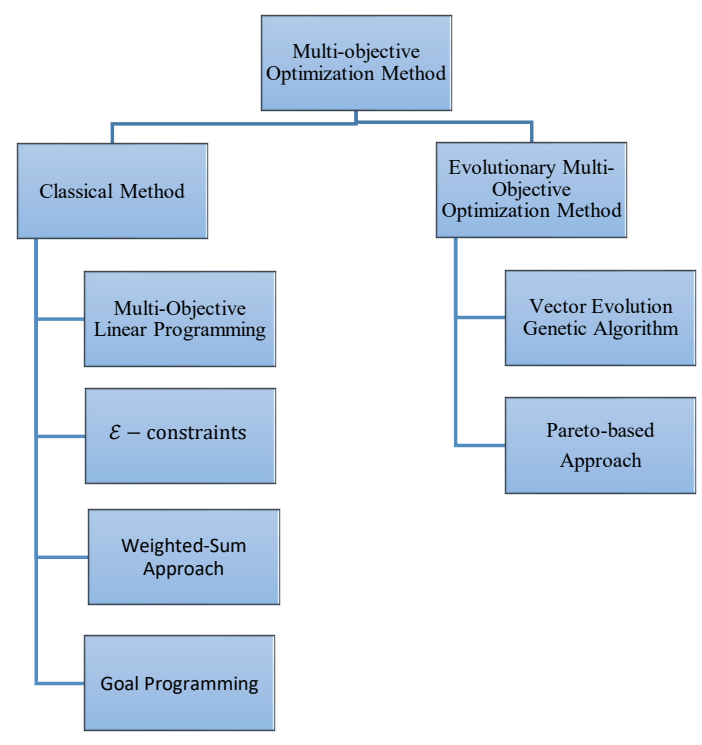

Figure 2 Some approaches for Multi-Objective Optimization

- Multi-objective is a vector of constraints, objective functions, and variables and is considered by Multiobjective Programming Model. A reduced subset of the feasible set exceeds all of the aspiration levels of each objective contains a satisfactory solution a set of which has acceptable alternatives that do not need to be nondominated. A final choice of a non-dominated solution selected through decision makers' involvement in the information processing stage is a preferred solution [26].

- $\varepsilon$-constraint methods are those of a posteriori using scalarization. By these methods, a multi-objective problem will be converted into a single-objective method and can solve the problem and obtain its solution as a Pareto-optimal single solution.

- Weighted Sum Approach is an easy method to apply to weighted specific functionalities and then combine the weight and objective functions to build a single objective but the problem of using this method is if there is not enough information, it will result in difficulty in defining the objective weight as can be seen from the research of [27].

- Goal Programming Approach is a method that rank evaluates a set of results which uses the stage of MultiObjective Goal Programming (MOGP), as can be seen from the research of [28] which presents that this method is well known in methodology and development of the proposal which has efficiency in defining goals (Multiple Goal Linear Programming-MGLP) that are trying to deviate between various objectives. The lowest formula is used in calculating outputs from various goals and compares those values until it gets the best results suitable for an allocation problem such as limited resources management [29].

- Vector Evaluation Approach is a method that defines Fitness Assignment which is the first method that expands the steps of Genetic Algorithms, which results 


\section{K. Phoksawt et al. / Advances in Science, Technology and Engineering Systems Journal Vol. 2, No. 3, 1363-1371 (2017)}

in finding the most appropriate results for various objectives. [30] explained the process consists of 1) Initialization Population 2) Evaluation Objective Function 3) Define Fitness Assignment 4) Selection of the results from the Fitness Assignment of strings: each result during this process will crossover. This is a process where a right string answer which comes paired to exchange to get the new string result and mutation to evaluate new strength until the calculation reaches the maximum number of answers looked for [31].

- Pareto-based Approach: This method is used to rank the Pareto to build relationships between the function, purpose, and strength by using the Pareto principle to calculate the strength. For how to configure the strength to make this the best result, it will have more than one possible result that could be the best answer and it will be in the format of set, or group of the best answers [32].

\section{Conceptual Framework}

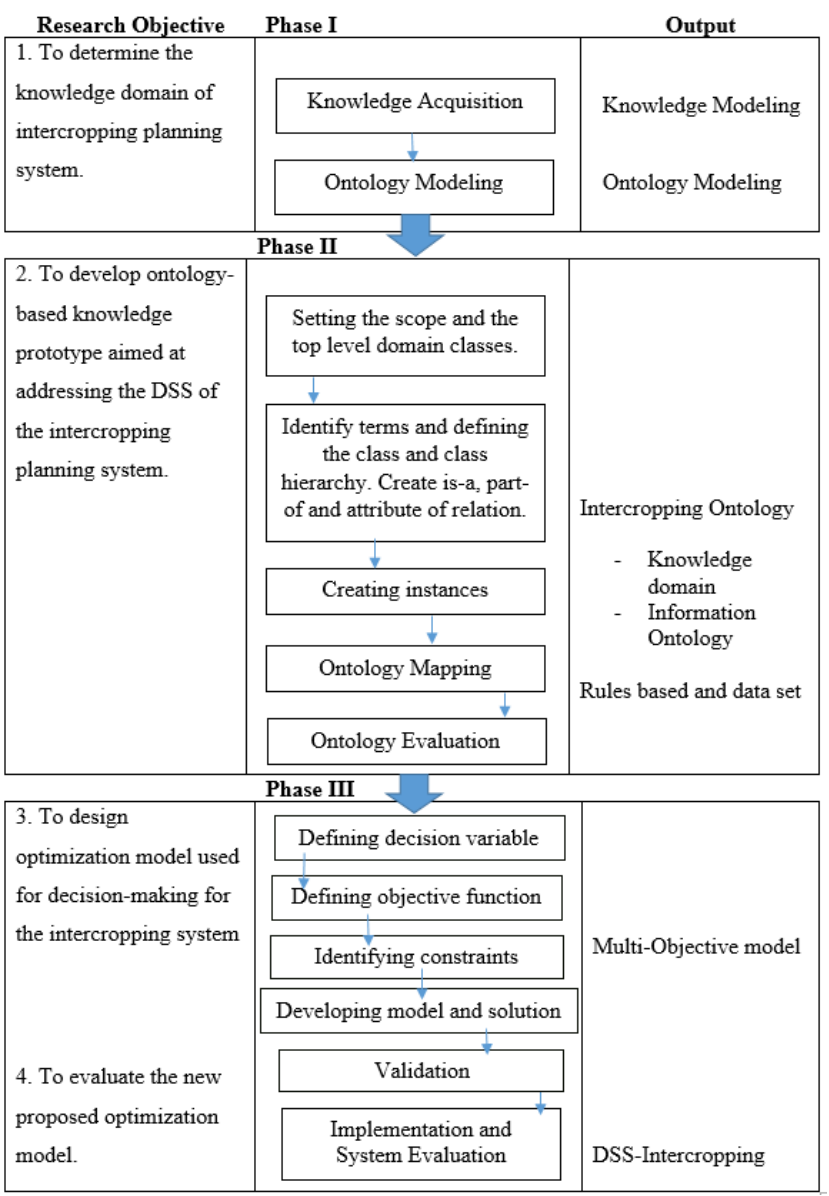

Figure 3 Research Conceptual Framework of DSS-Intercropping

The DSS for growing rubber plants is a hybrid method which works together in two parts. The knowledge-based part uses the process of knowledge management with ontology to obtain a rubber plantation model and to develop an intercropping ontology and rule base that will lead to a more intelligent recommender system which is mixed with a multi-objective optimization model part. It will helps to calculate and allocate each crop area to yield maximum yield and the lowest cost that the system will help farmers or users make decisions as a guideline or primary recommendations before making a decision on plantation operation as indicated by soil, time, season, area, cost, and market price or other critical parameters.

\section{Research Methodology}

The method of this work is divided into three main phases namely, Phase I knowledge acquisition and ontology modeling, Phase II ontology development, and Phase III optimization modeling and system implementation. This is shown in Figure 3 and details in each phase are presented in Sections 4.1, 4.2 and 4.3 , respectively.

\subsection{Phase I: Knowledge Acquisition and Ontology Modeling}

This research is information to extract knowledge and expert knowledge for decision making and decision criteria and a variety of organizations. The Ministry of Agriculture and Cooperatives of Thailand is the main organization for promoting agriculture. It was split into several entities with different responsibilities. In addition, certain information is required from other ministries. These are summarized as the sources of data for research purposes to support farmers for intercropping shown in Table 1.

Table 1 Summarized the sources of data to support decision making for intercropping

\begin{tabular}{lr}
\hline Organization & Type of information \\
\hline $\begin{array}{l}\text { Department of Agricultural } \\
\text { Extention }\end{array}$ & providing: \\
& - Knowledge and media for cropping \\
& - Disease and pets \\
Office of Agricultural & - Sale Price Statistic per kg (THB) \\
Economic & - Cost per square meters (THB) \\
& - Productivity per square meters (kg.)
\end{tabular}

Royal Irrigation Department The water situation and rainfall statistics.

Land Development Soil information each province

Department

Provincial Agriculture

Office

Advising agriculture in each province for intercropping.

Farmer who are success in intercropping

The information about intercropping from experience.

\section{Knowledge Acquisition}

In this section, the knowledge acquisition approach was a combination of text analysis and expert interview approach [33]. The study included three steps:

- Concept and domain knowledge. Identified using secondary resource document analysis e.g. electronic resources, journal, or book. Based on intercropping system principles, in this research merely three factors: spacing, cultivation period, plant disease will be employed as important factors. Selection of factors are also consistent with research that had been performed by a summary of factors from previous research and from the selection of sub rubber plantations booking to pursue an 


\section{K. Phoksawt et al. / Advances in Science, Technology and Engineering Systems Journal Vol. 2, No. 3, 1363-1371 (2017)}

alternative career at the Department of Agricultural Extension, Ministry of Agriculture and Cooperatives, Thailand which recommended considering the use of tree age criteria. In addition, due to time constraints of performing this research data some important related factors are already sufficiently provided and the high cost of extension of the research to other less important or less prioritized topics and the selection is based on recommendations provided by plant production experts. The selected factors are soil, spacing, time, and diseases. Spacing is important as individual plants require a different area for growth of root, and size of branching. These factors are expected to produce a significant impact on light, water and mineral resource use of plants. Time is a critical factor as well, and a proper arrangement or organization of short-term and long-term co-planted plants will cause an increased use and rate of light, and mineral resource for plants compared to single cropping that is usually suitable for some particular seasons and period of harvesting so as to generate constant revenue throughout the year. Even though mixing or intercropping may not produce complete immunity to related plants, as some diseases can destroy more than one type of plant in one single invasion, a selection of proper but different plants that usually can't be destroyed by the same diseases will much reduce a destruction rate of disease destruction. However, economic factors including price and cost need to be involved because the decisions affect production rates[8].

- Interview with experts who are in the areas of intercropping. Two groups classify the population and sample: (1) government agency officials obliged to provide agriculture information, and (2) farmers successful in intercropping. Purposive sampling from the population is used because they have to choose from the expertise of experienced farmers in the agricultural field and the knowledge and experience of rubber farmers in the province. So the experts came from two groups, the first group were five state employees from five agencies of the Ministry of Agriculture and Cooperatives. As depicted in Table 1, this is an agency that provides information related to agricultural extension which has a direct duty to provide advice on cropping for local farmers, and Group 2 are three farmers who have specialized and succeeded in intercropping in rubber plantations. After that drafting knowledge classification was categorized by evaluating the data types and characteristics of the data using a hierarchical clustering of intercropping system terms. Questions to ask are open-ended questions to extract knowledge of intercropping cultivation. The criterion for selecting a plant to plant with rubber are the age range of tree and plants suitable for growing any plant with the same plant disease, the risk of damage to the main crops or rubber trees. Then the draft knowledge domain is summarized to be verified in the next step.

- Knowledge domain and concept is summarized and results reconfirmed with the experts. Consider the appropriateness of the criteria and concepts that are included in the manual and from expert interviews. Then reconfirm from experts by the focus group method.

\section{Ontology Modeling}

Identifying terms of related information is required for the design of ontologies for intercropping which starts from defining the scope of knowledge about intercropping. A combination method is then used for the system to classify the terms into classes and hierarchy of class levels of ontology. Important concepts are sequenced first e.g. the selecting crops principle. For instance, requirements of co-planting plants in terms of disease and insect, soil, and these co-planting plants harvesting time should be overlapped to help farmers have a continuous or relatively constant revenue throughout a year. Then each class qualification is identified including heritage of classes consideration and defining conditions for qualification of a class. For example, classes types of qualifications are identified. The tool to build knowledge modeling is CmapTools. CmapTools collaboration and publishing features are used widely for sharing and representing all knowledge domains including organizing information, brainstorming and knowledge management.

\subsection{Phase II: Ontology Development and the Evaluation}

\section{Ontology Development}

The ontology life cycle has seven steps [34] but: "there is no one way or methodology for developing ontologies and ontology development is necessarily an iterative process." Ontology development should be based on application objectives, data characteristic, information system rules and context and future reuse feasibility [35]. The intercropping ontology will be developed using a top-down approach. This is a way to start with the concept of a generic domain which starts with the most common definitions based on concepts in the domain and take that expertise to be guidelines and define a specific concept. For example, starting by creating a class for the general idea of cropping. Then, create a subclass in that class and go to the bottom of the ontology structure which are instances or data, followed by the modeling:

- Setting the scope and the top level domain classes. To define scope and the top level domain classes it is defined in the field of intercropping and this ontology is used to make decisions in intercropping. It helps answer questions such as "What are characteristic of plants that can grow with rubber plantation?", "Which season is an appropriate season to plant?", "What is the cost and output per square meter?", and "What is the total revenue and cost?" Knowledge-based ontology development uses the ontology editor. Several software platforms and application interfaces (APIs) have been developed to support the Semantic Web vision of making machine-readable content available on the web to permit automatic creation and use of OWL and RDF. Currently there are many tools for ontologies editors such as Protégé, OntoEdit, OILDd, Hozo. However, Protégé is an open-source platform developed by Stanford University and is a kind of popular tool for ontology editor. Protégé is plug-in architecture that can 


\section{K. Phoksawt et al. / Advances in Science, Technology and Engineering Systems Journal Vol. 2, No. 3, 1363-1371 (2017)}

be adapted to build both simple and complex ontologybased applications. Developers can integrate to output of Protégé with rule systems or other problem solvers to construct a wide range of intelligent systems [36].

- Identify terms or concept and defining the class and class hierarchy. Create Is-a, Part-of and attribute-of relation. Examples of important terms or concepts in this work are such as economic crops, soil, water, plant diseases, seasons, etc. Define relationship between concept types $I s-A$ such as rubber is an economic plant. For Part-of relationship, for example, the address of the farmer consists of district, etc. Then define the properties of Concept (Term) such as rubber is a species, type of soil suitable for planting, plant diseases, yield per rai $\left(3000 \mathrm{~m}^{2}\right)$, price etc. There are two types of intrinsic property such as variation, appropriate soil type, planting period, plant disease, and 2 extrinsic properties such as cost and price.

- Creating data instances and ontology mapping. Recommender engine requires a rule engine to construct and additional criterion [37] applied JENA and SPARQL for developing the backend of this component [38].

\section{Ontology evaluation}

Assessment of ontology in this work is through clarity, completeness, consistency, and correctness criteria by ontology development experts. Based on an ontology evaluation by an expert also known as assessment by humans it can evaluate all 6 levels including lexical, taxonomy, semantic relations, application, syntactic, and design. When compared to Gold Standard, application-based, and data-driven evaluation [39] and the number of experts to use for validity, [40] advised a minimum of three experts, on the other hand indicated that more than ten was probably unnecessary [41]. Therefore, in evaluating the ontology in this research, it employs three developers with three to five years ontology experience. This step provided evaluation in terms of the concepts, and relationships related to the intercropping system and includes an accuracy evaluation of rules, a concept of result calculation, screening of cultivated plants suitable for a particular area as farmer requests and screening of co-planting plants are assessed by three experts by a comparison between system results and results obtained by experts' presented recommendation. Then it is improved before using an optimization model to calculate economic factor in the next step.

\subsection{Phase III: Optimization Modeling and Implementation}

\section{Optimization Modeling}

After creating the ontology-based knowledge to introduce crops that can be planted with major crops suited to an area by intercropping we will get parameters for design models and import data into the model including data from the database in the recommender system such as the type of crop, prices, and cost and input data from users consisting of: name, address, size of area, cost, and start of planting.
Because this problem is one of resource allocation which are land and cost the mathematical model used to solve this limited resource allocation problem, decision variables are objective functions or the limitations of the model. Each decision variable is often multiplied by a constant and then added as a function, objective or equation or inequality of constraints. These variables have a linear relationship. The models in this characteristic are called Linear models such as $x_{1}$ and $x_{2}$ instead of the $1^{\text {st }}$ and $2^{\text {nd }}$ crop where $z$ represents the profit or revenue from the sale of both crops. There are three main components: Decision variable, Objectives, and Constraints. A detailed explanation of the objective function and the constraints of the proposed model are given in the following sections.

\section{- Decision Variables}

From the problem, it is found that the farmers have to choose intercrop plants that fit their own space and resources. Therefore, the decision variable is what economic crops are suitable to grow with rubber trees and how much of the planted area will produce the highest yield and lowest cost. The calculation model contains two parts: Part 1 Data is added to the user's planting area of intercropping, identifying the district to determine the type of soil from the Land Development Department, the size of the area measured in square meters. Secondly one must determine which information is stored in the data set. This includes production per square meter, price (THB / kg.), cost per square meter, and the number of days it takes to grow. The result of this calculation, a multi-objective optimization model, is shown in the background of each type of crop, illustrating the potential highest income and lowest total cost.

\section{- Create the Objectives and Constraints}

Intercropping has several objectives to prevent pests, adding nutrients to increase productivity, mulch, help increase revenue before harvesting main crops, etc. [42]. However, [43] has studied factors of decision making for multiple crops or new theory farming practices of farmers in north-eastern, Thailand. It was found that the main factors that affected the changing behavior of decision making or the selection of crop system was the price or income and that most farmers' problems are capital, plant diseases and lacking irrigation. This is in line with the study by [44] which presented the factors affecting the decision to change the use of land or change the crops of farmers Thailand were revenue and costs. The problem is caused by the risk of price of output and the problems caused by the monoculture as mentioned above. Helping farmers get the highest annual income with lowest cost was the objective of this research through focusing on the allocation of space to grow various crops to increase revenue. Maximizing plant cultivation income and minimizing cost is the purpose of the model.

Many variables are used to calculate incomes for listed types of plantings as follows: particular productivity per square meter $\left(\mathrm{m}^{2}\right)$, sale price / kilogram (calculated as local currency as Thai currency), planting period starting from initial cultivation until harvested and cultivation period (month), area $\left(\mathrm{m}^{2}\right)$, related expenditure or production cost is calculated as sum of cost the individual productivity types (kilogram) multiplied by cultivation area $\left(\mathrm{m}^{2}\right)$. Constraints include size of the total area of the farm, where the number of plants will be not be equal to one. The 


\section{K. Phoksawt et al. / Advances in Science, Technology and Engineering Systems Journal Vol. 2, No. 3, 1363-1371 (2017)}

prototype consists of Decision Variable, Objective Function, and Constraints.

\section{- Developing Model and Validation Solution}

Multi-Objective Programming (MOP) is formulated with the objective of maximizing economic values obtained from an intercropping system as well as minimizing its cost. The optimal levels for various decisions regarding seeding and harvesting time periods and cultivation areas are determined by solving the MOP. The tool used in the test model is MATLAB.

MATLAB is a proprietary fourth-generation programming language developed by MathWorks and MATLAB provides a multi-paradigm numerical computing environment allowing $\mathrm{C}$, $\mathrm{C}++$, Java, Fortran and Python interfacing, user interface creation, algorithms implementation, data and function plotting and manipulations of matrices and offers tools for application development, visualization capabilities, data analysis and highperformance numerical computation [45].

The solution allows one to find an answer within the set area of the possible answers, to find a minimum or maximum of each function simultaneously. The result or best answer consists of $\mathrm{m}$ objectives and decision variables as you can see in Equation 1 written as general equations as:

$$
\text { Minimize (or maximize): }\left\{f_{1}(x), f_{2}(x), \ldots, f_{m}(x)\right\}
$$

where $x$ is a vector of decision variables

$$
f_{\mathrm{i}}(\mathrm{x}) \text { is objective function, where } i=1,2, \ldots, m
$$

Therefore, patterns of solving multi-objective optimization function is finding $x$ vector solutions within $m$ constraints as shown in Inequality 2 or within $m$ constraints as shown in Equation 3 that determines the possible solution area. This defines a set of possible solutions.

$$
\begin{gathered}
g_{i}(x) \leq 0, i=1,2, \ldots, m \\
h_{i}(x)=0, i=1,2, \ldots, m
\end{gathered}
$$

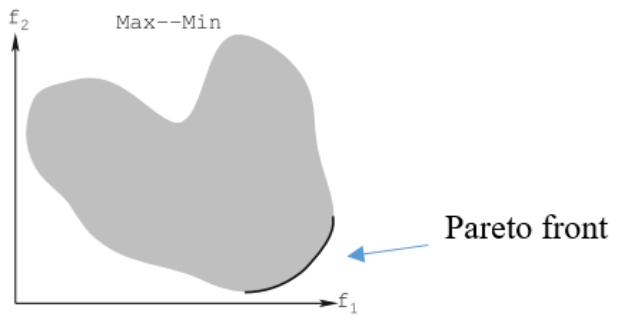

Figure 4 Pareto front of multi-objective functions $f_{1}$ (Max) and $f 2$ (Min)

[46] define the term Pareto Dominance and appropriate answer Pareto Optimality as seen below:
Definition 1: Pareto dominance: A given vector $u=$ $\left(u_{1}, \ldots, u_{m}\right)$ if and only if $\mathrm{u}$ is partially less than $v$. As can be seen in Equation 4:

$$
\forall_{i} \in\{1, \ldots, m\}, u_{i} \leq v_{i} \wedge \exists_{i} \in\{1, \ldots, m\}: u_{i}<v_{i}
$$

Where in the above equation $u$ and $v$ are defined.

Subsequently, there will also be some instances where $u$ is greater than $\mathrm{v}$.

"Definition 2: Pareto optimality: A solution $x_{u} \in[a, b]$ is said to be Pareto-optimal if and only if there is no $x_{v} \in u$ for which $v=f\left(x_{v}\right)=\left(v_{1}, \ldots, v_{m}\right)$ dominates $u=f\left(x_{u}\right)=\left(u_{1}, \ldots, u_{m}\right)$.

Pareto-optimal solutions are also called efficient, nondominate, and non-inferior solutions. The corresponding objective vectors are simply called non-dominated. The set of all nondominate vectors is known as the non-dominated set, or the tradeoff surface of the problem."

\section{Implementation and System Evaluation}

This stage includes coding and testing, installation and training and the final step is system evaluation. Knowledge-driven DSS uses a knowledge base extracted from the tacit knowledge of expert domain which makes the knowledge base available for interaction with decision makers by the structure of the MultiObjective Optimization model and the overall evaluation system. It is rule based to integrate with the data found in the system database and the decision maker's input to get the answer in planning rubber plantations.

- Checking to confirm the accuracy of recommender engine the introduction of intercropping planted with rubber. Using Ontology-based knowledge includes validation of agricultural information, agricultural economics, and the accuracy of the rule base. According to the principle of rubber plantation, using ontologybased knowledge in intercropping the ontology of the rubber plantation created consists of two parts: part 1 , the agricultural and agricultural economics data is the data of each economic crop such as harvesting season, harvesting Planting Period Planting Cost from data obtained from the public sector with reliable data storage and statistics and the experts in cropping are evaluating the validity of the criteria and parameters used in the model and rule based trust and knowledge validation mappings [47] by ontology development experts and intercropping experts. The validation solution by Mean Absolute Error (MAE) is used to calculate the rating difference between the actual and the predicted ratings.

$$
M A E=\frac{1}{n} \sum_{i=1}^{n}\left\lfloor y_{i}-\hat{y}_{i}\right\rfloor=\frac{1}{n} \sum_{i=1}^{n}\left\lfloor e_{i}\right\rfloor
$$

where:

$$
\begin{aligned}
& A E=\left|e_{i}\right|=\left|y_{i}-\hat{y}_{i}\right| \\
& \text { Actual }=y_{i} \\
& \text { Predicted }=\hat{y}_{i}
\end{aligned}
$$

- The data collection using a triangulation method was conducted by literature review, expert validation and 


\section{K. Phoksawt et al. / Advances in Science, Technology and Engineering Systems Journal Vol. 2, No. 3, 1363-1371 (2017)}

review, and user evaluation. The user evaluation focused on decision makers or users focused on decision makers' satisfaction. In order to evaluate overall satisfaction of DSS, the users were officers at various levels of the agricultural extension office such as provincial or district level from 23 districts. Thus, sampling of choice was multi-stage mixed random sampling and selection and the sampling was conducted by division of the sample into district level and purposive selection was made by officers who are responsible for giving related advice and recommendation. Statistics used in this case are mean $\bar{x}$ and standard deviation (s.d.).

\section{Conclusion and Future Work}

Ontology-based knowledge and multi-objective optimization programming to drive a decision support system for intercropping is based on constraint factors from an individual farmer for illustrating maximum income. The research methodology is divided into three phases as follows: (1) knowledge acquisition and ontology modeling. This methodology is based on knowledge's extraction from experts or specialists due to the fact of long experience based knowledge; (2) ontology development and recommender system is a creation of ontology as it is designed as well as a preparation of instance and ontology mapping as rules governing intercropping and evaluation and assessment of ontology; and the last stage is (3) design of multiobjective programming in order to obtain the answers of what types of plants should be planted, the proportion of each coplanting plants, overall generated revenue and production cost. The future work is knowledge acquisition and ontology modeling which is an important step to collect knowledge from experts and published papers issued by Department of Agriculture Extension, Ministry of Agriculture and Agricultural Co-operatives before being used for developing ontology at Phase II.

\section{Conflict of Interest}

The authors declare no conflict of interest.

\section{Acknowledgment}

Many thanks to Rajamangala University of Technology Srivijaya who sponsored the research grants and, also thanks to Nakhon Si Thammarat Agricultural Extension Office for the information and their time to explain about the problems of farmers.

\section{References}

[1] K. Phoksawat and M. Mahmuddin, "Ontology-based knowledge and optimization model for Decision Support System to intercropping," in 2016 International Computer Science and Engineering Conference (ICSEC), 2016, pp. 1-6. https://doi.org/10.1109/ICSEC.2016.7859927

[2] Office of Agricultural Economics, "Agricultural Statistics of Thailand 2015," 2015.

[3] Bank of Thailand, "Report on major agricultural price trends in southern Thailand," 2016.

[4] M. Stamp, "Risks of monoculture," Communication of the ACM, vol. 47, p. 120, 2004.

[5] S. R. Mousavi and H. Eskandari, "A general overview on intercropping and its advantages in sustainable agriculture," Journal of Applied Environmental and Biological Sciences, vol. 1, pp. 482-486, 2011.
[6] S. Arreeras, T. Angskun, and J. Angskun, "A Design of an Expert System for Intercropping Planning," in Proceedings of the 16th Tri-University International Joint Se miner and Symposium, 2009, pp. 19-22.

[7] A. Gadge, A. Kedar, and K. Aglawe, "Optimization of cost for farmers of cotton based farming system by Linear Programming Model," International Journal of Mechanical Engineering and Robotics Research, vol. 3, p. 505, 2014.

[8] C. Srisawat and J. Payakpate, "Comparison of MCDM Methods for Intercrop Selection in Rubber Plantatios," Journal of ICT, vol. 15, pp. 165-182, 2016.

[9] P. Worawimolwanich and K. Kesorn, "Decision Support System for Economic Crops using Hybrid Approaches," The eleventh National Conference on computing and Information Technology, pp. 425-431, 2015.

[10] A. S. Sodiya, A. T. Akinwale, K. A. Okeleye, and J. A. Emmanuel, "An Integrated Decision Support System for Intercropping," International Journal of Decision Support System Technology, vol. 2, pp. 51-66, 2010.

[11] J. C. Groot, G. J. Oomen, and W. A. Rossing, "Multi-objective optimization and design of farming systems," Agricultural Systems, vol. 110, pp. 63-77, 2012

[12] Y.-C. Chang, P.-P. Lee, and C.-E. Kan, "Farm-level land diversity of smallholders with limited input resources during urbanization in Taiwan," Paddy and water environment, vol. 12, pp. 155-162, 2014.

[13] D. J. Power, R. Sharda, and F. Burstein, Decision support systems: Wiley Online Library, 2015.

[14] K. Asanee, "Ontology Engineering and Knowledge Services for Agriculture Domain," Journal of Integrative Agriculture, vol. 11(5), pp. 741-751, 2012.

[15] S. Barthel and C. Isendahl, "Urban gardens, agriculture, and water management: Sources of resilience for long-term food security in cities," Ecological Economics, vol. 86, pp. 224-234, 2013.

[16] A. Dawson, D. Brown, and V. Broughton, "The need for a faceted classification as the basis of all methods of information retrieval," in Aslib proceedings, 2006, pp. 49-72.

[17] M. R. a. L. Serafini, "An Ontological Framework for Decision Support," Springer-Verlag Berlin Heidelberg, pp. 239-254, 2013.

[18] B. Wouters, D. Deridder, and E. Van Paesschen, "The use of ontologies as a backbone for use case management," in European Conference on ObjectOriented Programming (ECOOP 2000), Workshop: Objects and Classifications, a natural convergence, 2000.

[19] H.-J. Happel and S. Seedorf, "Applications of ontologies in software engineering," in Proc. of Workshop on Sematic Web Enabled Software Engineering"(SWESE) on the ISWC, 2006, pp. 5-9. https://doi.org/10.1.1.89.5733

[20] X. Chang, L. Zheng, and J. Terpenny, "Ontology Development and Optimization for Data Integration and Decision-Making in Product Design and Obsolescence Management," in Ontology Modeling in Physical Asset Integrity Management, ed: Springer, 2015, pp. 87-132.

[21] R. Saa, A. Garcia, C. Gomez, J. Carretero, and F. Garcia-Carballeira, "An ontology-driven decision support system for high-performance and costoptimized design of complex railway portal frames," Expert Systems with Applications, $\quad$ vol. $\quad 39, \quad$ pp. 8784-8792, 2012. https://doi.org/10.1016/j.eswa.2012.02.002

[22] D. Fensel, "Ontology-based knowledge management," Computer, vol. 35, pp. 56-59, 2002.

[23] A. Thunkijjanukij, A. Kawtrakul, S. Panichsakpatana, and U. Veesommai, "Ontology development: a case study for Thai rice," Kasetsart Journal (Natural Science), vol. 43, pp. 594-604, 2009.

[24] S. Y. Mawardi, M. H. Abdel-Aziz, A. M. Omran, and T. A. Mahmoud, "An Ontology-Driven Decision Support System for Wheat Production," International Journal of Computer Science and Telecommunications, vol. 4, pp. 11-17, 2013.

[25] K. Deb, "Multi-objective optimization," in Search methodologies, ed: Springer, 2014, pp. 403-449. https://doi,org/10.1007/978-1-4614-69407 15

[26] G. Zhang, J. Lu, and Y. Gao, Multi-Level Decision Making: Springer, 2015.

[27] P. V. Radtke, T. Wong, and R. Sabourin, "A multi-objective memetic algorithm for intelligent feature extraction," in International Conference on Evolutionary Multi-Criterion Optimization, 2005, pp. 767-781. 
[28] F. Blancas, R. Caballero, M. González, M. Lozano-Oyola, and F. Pérez, "Goal programming synthetic indicators: An application for sustainable tourism in Andalusian coastal counties," Ecological Economics, vol. 69, pp. 2158-2172, 2010.

[29] B. Mishra and S. Singh, "Optimal Land Allocation in Agricultural Production Planning Using Fuzzy Goal Programming," in Proceedings of Fifth International Conference on Soft Computing for Problem Solving, 2016, pp. 287-298. https://doi.org/ 10.1007/978-981-10-0448-3_23

[30] J. D. Schaffer, "Some experiments in machine learning using vector evaluated genetic algorithms," Vanderbilt Univ., Nashville, TN (USA)1985.

[31] P. Ammaruekarat and P. Meesad, "Multi-Objective Optimization using Evolutionary Algorithms," Information Technology Journal, vol. 8, pp. 7380, July-December 20122012.

[32] Z. He, G. G. Yen, and J. Zhang, "Fuzzy-based Pareto optimality for manyobjective evolutionary algorithms," IEEE Transactions on Evolutionary Computation, vol. 18, pp. 269-285, 2014. https://doi.org/ 10.1109/TEVC.2013.2258025

[33] Y. I. Liou, "Expert system technology: knowledge acquisition," The handbook of applied expert systems, pp. 2.1-2.11, 1999.

[34] N. F. Noy and D. L. McGuinness, "Ontology development 101: A guide to creating your first ontology," ed: Stanford knowledge systems laboratory technical report KSL-01-05 and Stanford medical informatics technical report SMI-2001-0880, Stanford, CA, 2001.

[35] N. Kaewboonma, K. Tuamsuk, and W. Kanarkard, "Ontology development for drought management information," International Journal of Metadata, Semantics and Ontologies, vol. 9, pp. 324-332, 2014. https://doi.org/10.1504/IJMSO.2014.065443

[36] H. A. Salah, "Ontology development (OWL\&UML) methodology of webbased Decision Support System for water management," in Electronics, Computers and Artificial Intelligence (ECAI), 2014 6th International Conference on, 2014, pp. 11-22. https://doi.org/ 10.1109/ECAI.2014.7090217

[37] T. Supnithi, P. Paiboonrat, M. Buranarach, A. Kawtrakul, S. Lekawatana, A. Intalak, et al., "Ontology Based Orchid Knowledge Platform for Knowledge Services in Orchid Cluster," in 2011 Annual SRII Global Conference, 2011, pp. 540-549. https://doi.org/ 10.1109/SRII.2011.62

[38] Y.-F. Zhang, L. Gou, Y. Tian, T.-C. Li, M. Zhang, and J.-S. Li, "Design and Development of a Sharable Clinical Decision Support System Based on a Semantic Web Service Framework," Journal of medical systems, vol. 40, pp. 1-14, 2016. https://doi.org/10.1016/ j.cmpb.2015.90.020

[39] H. Hlomani and D. Stacey, "Approaches, methods, metrics, measures, and subjectivity in ontology evaluation: A survey," Semantic Web Journal, pp. $1-5,2014$.

[40] M. R. Lynn, "Determination and quantification of content validity," Nursing research, vol. 35, pp. 382-386, 1986.

[41] D. F. Polit and C. T. Beck, "The content validity index: are you sure you know what's being reported? Critique and recommendations," Research in nursing \& health, vol. 29, pp. 489-497, 2006. https://doi.org/10.1002/nur.20147

[42] Department of Agriculture Extension, "Alternatives way for small pararubber farmers as supplemented revenue," 2014.

[43] W. Phromthong, "Factors of Decision Making on New Theory Farming Practices by Farmers in North-Eastern Region of Thailand," 2008.

[44] P. Muangmoon, "Land use changes from expansion of rubber plantation in Chattrakan, Phitsanulok," 2015.

[45] H. Aithal, O. Kumar, and M. R. Narasimhan, "Introducing Complex Software Design in MATLAB via Enterprise Architect," in Engineering and Technology (ICETECH), 2016 IEEE International Conference on, 2016, pp. 981-983. https://doi.org/ 10.1109/ICETECH.2016.7569396

[46] C. M. Fonseca and P. J. Fleming, "Multiobjective optimization and multiple constraint handling with evolutionary algorithms. I. A unified formulation," IEEE Transactions on Systems, Man, and Cybernetics-Part A: Systems and Humans, vol. 28, pp. 26-37, 1998.

[47] A. Vermesan and F. Coenen, Validation and Verification of Knowledge Based Systems: Theory, Tools and Practice: Springer Science \& Business Media, 2013. 